\title{
Front Matter: Volume 8140
}

, "Front Matter: Volume 8140," Proc. SPIE 8140, X-ray Lasers and Coherent X-ray Sources: Development and Applications IX, 814001 (12 December 2011); doi: 10.1117/12.914861

SPIE Event: SPIE Optical Engineering + Applications, 2011, San Diego, California, SPIE. United States 


\section{PROCEEDINGS OF SPIE}

\section{$X$-ray Lasers and Coherent $X$-ray Sources: Development and Applications IX}

James Dunn

Annie Klisnick

Editors

23-25 August 2011

San Diego, California, United States

Sponsored and Published by

SPIE

Volume 8140 
The papers included in this volume were part of the technical conference cited on the cover and title page. Papers were selected and subject to review by the editors and conference program committee. Some conference presentations may not be available for publication. The papers published in these proceedings reflect the work and thoughts of the authors and are published herein as submitted. The publisher is not responsible for the validity of the information or for any outcomes resulting from reliance thereon.

Please use the following format to cite material from this book:

Author(s), "Title of Paper," in X-ray Lasers and Coherent X-ray Sources: Development and Applications IX, edited by James Dunn, Annie Klisnick, Proceedings of SPIE Vol. 8140 (SPIE, Bellingham, WA, 2011) Article CID Number.

ISSN 0277-786X

ISBN 9780819487506

Published by

SPIE

P.O. Box 10, Bellingham, Washington $98227-0010$ USA

Telephone +1 3606763290 (Pacific Time) · Fax +1 3606471445

SPIE.org

Copyright (@ 2011, Society of Photo-Optical Instrumentation Engineers

Copying of material in this book for internal or personal use, or for the internal or personal use of specific clients, beyond the fair use provisions granted by the U.S. Copyright Law is authorized by SPIE subject to payment of copying fees. The Transactional Reporting Service base fee for this volume is $\$ 18.00$ per article (or portion thereof), which should be paid directly to the Copyright Clearance Center (CCC), 222 Rosewood Drive, Danvers, MA 01923. Payment may also be made electronically through CCC Online at copyright.com. Other copying for republication, resale, advertising or promotion, or any form of systematic or multiple reproduction of any material in this book is prohibited except with permission in writing from the publisher. The CCC fee code is 0277-786X/11/\$18.00.

Printed in the United States of America.

Publication of record for individual papers is online in the SPIE Digital Library.

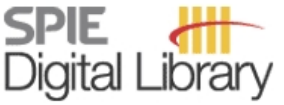

SPIEDigitalLibrary.org

Paper Numbering: Proceedings of SPIE follow an e-First publication model, with papers published first online and then in print and on CD-ROM. Papers are published as they are submitted and meet publication criteria. A unique, consistent, permanent citation identifier (CID) number is assigned to each article at the time of the first publication. Utilization of CIDs allows articles to be fully citable as soon as they are published online, and connects the same identifier to all online, print, and electronic versions of the publication. SPIE uses a six-digit CID article numbering system in which:

- The first four digits correspond to the SPIE volume number.

- The last two digits indicate publication order within the volume using a Base 36 numbering system employing both numerals and letters. These two-number sets start with 00, 01, 02, 03, 04 , 05, 06, 07, 08, 09, OA, OB ... 0Z, followed by 10-1Z, 20-2Z, etc.

The CID number appears on each page of the manuscript. The complete citation is used on the first page, and an abbreviated version on subsequent pages. Numbers in the index correspond to the last two digits of the six-digit CID number. 


\title{
Contents
}

\author{
ix Conference Committee \\ xi Introduction \\ xiii Biomedical spectral x-ray imaging: promises and challenges (Plenary Paper) [8143-100] \\ S. M. Jorgensen, D. R. Eaker, E. R. Ritman, Mayo Clinic College of Medicine (United States)
}

\section{SESSION 1 FREE ELECTRON LASERS}

814003 Using the X-FEL to photo-pump x-ray laser transitions in He-like Ne [8140-04]

J. Nilsen, Lawrence Livermore National Lab. (United States); N. Rohringer, Ctr. for Free

Electron Laser Science (Germany)

\section{SESSION 2 SEEDING OF X-RAY LASERS}

814005 Advances in laser driven soft x-ray lasers at LOA (Invited Paper) [8140-06]

S. Sebban, F. Tissandier, J. Gautier, M. Kozlova, J. P. Goddet, Lab. d'Optique Appliquée, CNRS, École Polytechnique ParisTech (France); O. Guilbaud, Lab. de Physique des Gaz et des Plasmas, CNRS, Univ. Paris-Sud 11 (France); P. Zeitoun, M. Ribière, Lab. d'Optique Appliquée, CNRS, École Polytechnique ParisTech (France); S. Jacquemot, École Polytechnique (France); G. Lambert, Lab. d'Optique Appliquée, CNRS, École Polytechnique ParisTech (France); G. Maynard, B. Robillard, Lab. de Physique des Gaz et des Plasmas, CNRS, Univ. Paris-Sud 11 (France); A. Klisnick, ISMO, CNRS, Univ. Paris-Sud 11 (France); T. Mocek, J. Nejdl, Institute of Physics of the ASCR, v.v.i. (Czech Republic)

814006 Spectral width of seeded and ASE XUV lasers: experiment and numerical simulations [8140-07]

A. Klisnick, L. M. Meng, ISMO, CNRS, Univ. Paris-Sud 11 (France); D. Alessi, Colorado State Univ. (United States); O. Guilbaud, LASERIX-CLUPS, CNRS, Univ. Paris-Sud 11 (France) and Lab. de Physique des Gaz et des Plasmas, CNRS, Univ. Paris-Sud 11 (France);

Y. Wang, M. Berrill, B. Luther, Colorado State Univ. (United States); A. Calisti, Lab. PIIM, CNRS, Aix-Marseille Univ. (France); D. Benredjem, Lab. Aimé Cotton, CNRS, Univ. Paris-Sud 11 (France); S. Ferri, C. Mossé, Lab. PIIM, CNRS, Aix-Marseille Univ. (France); S. de Rossi, D. Joyeux, Lab. Charles Fabry de I'Institut d'Optique (France); J. J. Rocca, Colorado State Univ. (United States) 
814007 Fully coherent, wake and ASE-suppressed $15 \mu \mathrm{J}, 120$ fs amplified high order harmonic pulse demonstrated with 1D time-dependant Bloch-Maxwell code [8140-08]

E. Oliva, Lab. d'Optique Appliquée, CNRS, École Polytechnique ParisTech (France) and Univ. Politécnica de Madrid (Spain); P. Zeitoun, Lab. d'Optique Appliquée, CNRS, École Polytechnique ParisTech (France); M. Fajardo, Lab. d'Optique Appliquée, CNRS, École Polytechnique ParisTech (France) and Instituto Superior Tecnico (Portugal); P. Velarde, Univ. Politécnica de Madrid (Spain) and Lab. d'Optique Appliquée, CNRS, École Polytechnique ParisTech (France); D. Ros, CLUPS, CNRS, Univ. Paris-Sud 11 (France); S. Sebban, Lab. d'Optique Appliquée, CNRS, École Polytechnique ParisTech (France)

814008 Signal build-up from noise and seeding in plasma-based x-ray lasers (Invited Paper) [8140-09]

C. M. Kim, K. Janulewicz, Gwangju Institute of Science and Technology (Korea, Republic of); H. Stiel, Max Born Institute (Germany); M. Nishikino, N. Hasegawa, T. Kawachi, Japan Atomic Energy Agency (Japan); J. Lee, Gwangju Institute of Science and Technology (Korea, Republic of)

814009 Strong field amplification of XUV: phase matching aspects [8140-10] J. Seres, Friedrich-Schiller-Univ. Jena (Germany); E. Seres, Friedrich-Schiller-Univ. Jena (Germany) and Helmholtz Institute Jena (Germany); B. Ecker, Helmholtz Institute Jena (Germany), GSI Helmholtzzentrum für Schwerionenforschung(Germany), and Johannes Gutenberg Univ. Mainz (Germany); B. Landgraf, Friedrich-Schiller-Univ. Jena (Germany) and Helmholtz Institute Jena (Germany); D. Hochhaus, GSI Helmholtzzentrum für Schwerionenforschung(Germany), Extreme Matter Institute (Germany), and Johann Wolfgang Goethe-Univ. Frankfurt am Main (Germany); D. Zimmer, GSI Helmholtzzentrum für Schwerionenforschung(Germany) and Johannes Gutenberg Univ. Mainz (Germany); V. Bagnoud, GSI Helmholtzzentrum für Schwerionenforschung (Germany); B. Aurand, GSI Helmholtzzentrum für Schwerionenforschung(Germany), Johannes Gutenberg Univ. Mainz (Germany), and Extreme Matter Institute (Germany); B. Zielbaver, Helmholtz Institute Jena (Germany), GSI Helmholtzzentrum für Schwerionenforschung(Germany), and Johannes Gutenberg Univ. Mainz (Germany); T. Kuehl, GSI Helmholtzzentrum für Schwerionenforschung(Germany) and Johannes Gutenberg Univ. Mainz (Germany); C. Spielmann, Friedrich-Schiller-Univ. Jena (Germany) and Helmholtz Institute Jena (Germany)

\section{SESSION 3 HARMONICS AND SHORT WAVELENGTH LASERS}

8140 0A Coherent $x$-ray generation in relativistic laser/gas jet interactions (Invited Paper) [8140-1 1] A. S. Pirozhkov, M. Kando, T. Zh. Esirkepov, Japan Atomic Energy Agency (Japan); P. Gallegos, Rutherford Appleton Lab. (United Kingdom) and Univ. of Strathclyde (United Kingdom); H. Ahmed, Queen's Univ. Belfast (United Kingdom); E. N. Ragozin, P.N. Lebedev Physical Institute (Russian Federation) and Moscow Institute of Physics and Technology (State Univ.) (Russian Federation); A. Ya. Faenov, T. A. Pikuz, Japan Atomic Energy Agency (Japan) and Joint Institute for High Temperatures (Russian Federation); J. K. Koga, H. Kiriyama, Japan Atomic Energy Agency (Japan); P. McKenna, Univ. Of Strathclyde (United Kingdom); M. Borghesi, Queen's Univ. Belfast (United Kingdom); K. Kondo, H. Daido, Japan Atomic Energy Agency (Japan); Y. Kato, The Graduate School for the Creation of New Photonics Industries (Japan); D. Neely, Rutherford Appleton Lab. (United Kingdom) and Univ. of Strathclyde (United Kingdom); S. V. Bulanov, Japan Atomic Energy Agency (Japan), Moscow Institute of Physics and Technology (State Univ.) (Russian Federation), and A. M. Prokhorov Institute of General Physics (Russian Federation) 
8140 OD Circularly polarized high order harmonics in the EUV photon energy range: toward table-top nanometric magnetic imaging [8140-14]

B. Vodungbo, A. Barszczak Sardinha, J. Gautier, G. Lambert, S. Sebban, Lab. d'Optique Appliquée, CNRS, École Polytechnique ParisTech (France); J. Lüning, Lab de Chimie Physique, CNRS, Univ. Pierre et Marie Curie (France); P. Zeitoun, Lab. d'Optique Appliquée, CNRS, École Polytechnique ParisTech (France)

\section{SESSION 4 X-RAY LASER APPLICATIONS I}

$8140 \mathrm{OE} \quad$ Stable and long-time operation of a soft $\mathrm{x}$-ray laser for user applications experiments (Invited Paper) [8140-15]

D. Ros, O. Guilbaud, S. Kazamias, M. Pittman, K. Cassou, S. Daboussi, O. Neveu, LASERIX-CLUPS, CNRS, Univ. Paris-Sud 11 (France) and Lab. de Physique des Gaz et des Plasmas, CNRS, Univ. Paris-Sud 11 (France); J. Demailly, B. Cros, G. Maynard, Lab. de Physique des Gaz et des Plasmas, CNRS, Univ. Paris-Sud 11 (France); B. Zielbauer, LASERIX-CLUPS, CNRS, Univ. Paris-Sud 11 (France) and GSI Helmholtzzentrum für Schwerionenforschung (Germany); D. Zimmer, LASERIX-CLUPS, CNRS, Univ. Paris-Sud 11 (France), GSI Helmholtzzentrum für Schwerionenforschung (Germany), and Johannes Gutenberg Univ. Mainz (Germany); T. Kühl, GSI Helmholtzzentrum für Schwerionenforschung (Germany) and Johannes Gutenberg Univ. Mainz (Germany); S. Lacombe, A. Klisnick, ISMO, CNRS, Univ. Paris-Sud 11 (France); S. Bastiani-Ceccoti, Lab. pour I'Utilisation des Lasers Intenses, CNRS, École Polytechnique (France); G. J. Tallents, E. Wagenaars, L. Wilson, The Univ. of York (United Kingdom); Ph. Zeitoun, Lab. d'Optique Appliquée, CNRS, École Polytechnique ParisTech (France)

8140 OF Heating of high energy density plasmas using EUV and x-ray lasers [8140-16] G. J. Tallents, D. S. Whittaker, L. A. Wilson, E. Wagenaars, The Univ. of York (United Kingdom)

$81400 \mathrm{O}$ Observation of the laser-induced surface dynamics by the single-shot $x$-ray laser interferometer [8140-17]

N. Hasegawa, Y. Ochi, T. Kawachi, M. Nishikino, M. Ishino, T. Imazono, T. Kaihori, A. Sasaki, Japan Atomic Energy Agency (Japan); K. Terakawa, Y. Minami, The Univ. of Tokyo (Japan); T. Tomita, M. Yamamoto, Y. Umeda, Univ. of Tokushima (Japan); M. Yamagiwa, Japan Atomic Energy Agency (Japan); T. Suemoto, The Univ. of Tokyo (Japan)

$8140 \mathrm{OH} \quad$ Coherent soft $x$-ray sources for users [8140-18]

O. Guilbaud, D. Ros, S. Kazamias, K. Cassou, S. Daboussi, LASERIX-CLUPS, CNRS, Univ. Paris-Sud 11 (France) and Lab. de Physique des Gaz et des Plasmas, CNRS, Univ. Paris-Sud 11 (France); M. Pitmann, LASERIX-CLUPS, CNRS, Univ. Paris-Sud 11 (France); J.-C. Lagron, B. Cros, LASERIX-CLUPS, CNRS, Univ. Paris-Sud 11 (France) and Lab. de Physique des Gaz et des Plasmas, CNRS, Univ. Paris-Sud 11 (France); G. Maynard, Lab. de Physique des Gaz et des Plasmas, CNRS, Univ. Paris-Sud 11 (France)

\section{SESSION 5 PLASMA-BASED X-RAY LASER SOURCES I}

$814001 \quad$ Advances in high repetition rate table-top soft x-ray lasers (Invited Paper) [8140-19] J. J. Rocca, Y. Wang, D. Alessi, B. A. Reagan, B. M. Luther, A. H. Curtis, K. Wernsing, F. Furch, M. R. Woolston, D. H. Martz, V. N. Shlyaptsev, M. Berrill, Colorado State Univ. (United States) 
8140 0J Towards high photon-number soft $x$-ray lasers [8140-20]

B. Ecker, Helmholtz Institute Jena (Germany) and Johannes Gutenberg Univ. Mainz (Germany); B. Aurand, Johannes Gutenberg Univ. Mainz (Germany), Extreme Matter Institute (Germany) and GSI Helmholtzzentrum für Schwerionenforschung (Germany); D. C. Hochhaus, Extreme Matter Institute (Germany); T. Kuehl, Johannes Gutenberg Univ. Mainz (Germany) and GSI Helmholtzzentrum für Schwerionenforschung (Germany); P. Neumayer, Extreme Matter Institute (Germany); H. Zhao, Helmholtz Institute Jena (Germany); B. Zielbaver, GSI Helmholtzzentrum für Schwerionenforschung (Germany); K. Cassou, S. Daboussi, O. Guilbaud, S. Kazamias, D. Ros, LASERIX-CLUP, CNRS, Univ. Paris-Sud 11 (France) and Lab. de Physique des Gaz et des Plasmas, CNRS, Univ. Paris-Sud 11 (France); E. Oliva, T. Le, P. Zeitoun, Lab. d'Optique Appliquée, CNRS, École Polytechnique ParisTech (France)

8140 OK Bloch-Maxwell modelling of multi- $\mathrm{mJ} 100 \mathrm{fs}$ fully coherent amplified high harmonic pulse (Invited Paper) [8140-21]

Ph. Zeitoun, E. Oliva, Lab. d'Optique Appliquée, CNRS, École Polytechnique ParisTech (France); M. Fajardo, Univ. Técnica de Lisboa (Portugal); T. T. T. Le, Lab. d'Optique Appliquée, CNRS, École Polytechnique ParisTech (France); D. Ros, CLUPS, CNRS, Univ. Paris-Sud 11 (France); S. Sebban, Lab. d'Optique Appliquée, CNRS, École Polytechnique ParisTech (France); P. Velarde, Univ. Politécnica de Madrid (Spain)

\section{SESSION 6 FREE ELECTRON LASERS: EXPERIMENTS AND DIAGNOSTICS}

814000 Spectroscopic studies of hard $\mathrm{x}$-ray free-electron laser-heated foils at $10^{16} \mathrm{Wcm}^{-2}$ irradiances [8140-25]

J. Dunn, R. Shepherd, A. Graf, A. Steel, J. Park, S. J. Moon, Lawrence Livermore National Lab. (United States); R. W. Lee, Lawrence Livermore National Lab. (United States) and SLAC National Accelorator Lab. (United States); P. Audebert, A. Levy, M. Gauthier, J. Fuchs, Lab. pour l'Utilisation des Lasers Intenses, École Polytechnique (France); D. M. Fritz,

M. Cammarata, D. Milathianaki, H. J. Lee, B. Nagler, SLAC National Accelerator Lab. (United States); C. Fourment, F. Deneuville, CELIA, CNRS, Univ. Bordeaux 1 (France); G. Williams, M. Fajardo, Univ. Técnica de Lisboa (Portugal); J. Gaudin, European XFEL GmbH (Germany); S. Vinko, O. Ciricosta, J. Wark, Univ. of Oxford (United Kingdom); H. K. Chung, International Atomic Energy Agency (Austria)

$81400 Q \quad$ A single-shot intensity-position monitor for hard x-ray FEL sources [8140-27]

Y. Feng, J. M. Feldkamp, D. M. Fritz, M. Cammarata, R. Aymeric, C. Caronna, H. T. Lemke, D. Zhu, S. Lee, S. Boutet, G. Williams, SLAC National Accelerator Lab. (United States); K. Tono, M. Yabashi, RIKEN (Japan); J. B. Hastings, SLAC National Accelerator Lab. (United States)

\section{SESSION $7 \quad$ X-RAY LASER APPLICATIONS II}

8140 OR Identification of Auger electron heating and inverse Auger effect in experiments irradiating solids with XUV free electron laser radiation at intensities larger than $10^{16} \mathbf{W} / \mathrm{cm}^{2}$ [8140-02]

F. B. Rosmej, Univ. Pierre et Marie Curie (France) and Lab. pour l'Utilisation des Lasers Intenses, École Polytechnique (France); F. Petitdemange, Univ. Pierre et Marie Curie (France); E. Galtier, SLAC National Accelerator Lab. (United States) 
8140 OT Table top nanopatterning by de-magnified Talbot effect using a capillary discharge soft x-ray laser [8140-29]

L. Urbanski, Colorado State Univ. (United States); P. Wachulak, Military Univ. of Technology (Poland); A. Isoyan, Synopsys, Inc. (United States); C. S. Menoni, J. J. Rocca, M. Marconi, Colorado State Univ. (United States)

$8140 \mathrm{OV}$ Theoretical study of coherent reflection imaging at grazing angles [8140-31]

I. A. Artyukov, S. I. Mikhailov, N. L. Popov, A. V. Vinogradov, P.N. Lebedev Physical Institute (Russian Federation)

8140 oW Assessment of illumination characteristics of soft $x$-ray laser-based full-field microscopes [8140-32]

I. D. Howlett, F. Brizuela, S. Carbajo, D. Peterson, Colorado State Univ. (United States); A. Sakdinawat, Y. Liu, D. T. Attwood, Colorado State Univ. (United States) and Univ. of California, Berkeley (United States); M. C. Marconi, J. J. Rocca, C. S. Menoni, Colorado State Univ. (United States)

\section{SESSION 8 PLASMA-BASED X-RAY LASER SOURCES II}

8140 0X Sub-10-nm wavelength Ni-like-ion collisional x-ray lasers (Invited Paper) [8140-33]

J. E. Balmer, F. Staub, C. Imesch, D. Bleiner, Univ. Bern (Switzerland)

8140 OY Line width measurement of a capillary discharge soft x-ray laser [8140-34]

L. Urbanski, Colorado State Univ. (United States); L. M. Meng, ISMO, CNRS, Univ. Paris-Sud 11 (France); M. C. Marconi, M. Berril, Colorado State Univ. (United States); O. Guilbaud, Lab. de Physique des Gaz et des Plasmas, CNRS, Univ. Paris-Sud 11 (France); A. Klisnick, ISMO, CNRS, Univ. Paris-Sud 11 (France); J. J. Rocca, Colorado State Univ. (United States)

$81400 Z$ Polarization measurements of plasma excited $x$-ray lasers [8140-35]

A. Aquila, Deutsches Elektronen-Synchrotron (Germany); D. Bleiner, J. Balmer, Univ. Bern (Switzerland); S. Bajt, Deutsches Elektronen-Synchrotron (Germany)

POSTER SESSION

$814011 \quad$ Ne-like Ti X-ray laser driven by a single femtosecond laser [8140-37]

Y.-J. Li, Y.-Q. Sun, China Univ. of Mining and Technology (China) and Institute of Physics

(China); A. Teng, China Univ. of Mining and Technology (China)

814012 Dynamics of the ultrashort laser pulse in a capillary discharge-preformed argon plasma channel [8140-38]

S. Sakai, J. Miyazawa, Utsunomiya Univ. (Japan); T. Higashiguchi, N. Yugami, Utsunomiya Univ. (Japan) and Japan Science and Technology Agency, CREST (Japan); N. Bobrova, P. Sasorov, Institute for Theoretical and Experimental Physics (Russian Federation)

814014 EUV microscopy using a lab-scale x-ray laser source [8140-40]

D. Bleiner, F. Staub, J. E. Balmer, Univ. Bern (Switzerland)

814015 Repetitive XUV laser based on the fast capillary discharge [8140-41]

J. Schmidt, K. Kolacek, O. Frolov, V. Prukner, J. Straus, Institute of Plasma Physics of the ASCR, v.v.i. (Czech Republic) 
814016 Time-resolved XUV radiation diagnostics from nitrogen discharge Z-pinch plasma [81 40-42] M. Nevrkla, A. Jancarek, J. Hübner, Czech Technical Univ. in Prague (Czech Republic);

D. Sheftman, Technion-Israel Institute of Technology (Israel); L. Pina, Czech Technical Univ. in Prague (Czech Republic); P. Vrba, Institute of Plasma Physics of the ASCR, v.v.i. (Czech Republic); M. Vrbova, Czech Technical Univ. in Prague (Czech Republic)

814017 Formation mechanism of non-uniform structure in the gain distribution and its effect to the plasma $x$-ray lasers [8140-43]

A. Sasaki, Japan Atomic Energy Agency (Japan)

8140 1A Characterization of the temporal duration of the XUV laser pulse at the LASERIX facility [8140-46]

L. Meng, ISMO, CNRS, Univ. Paris-Sud 11 (France); A.-C. Bourgaux, S. Bastiani-Ceccotti, Lab. pour l'Utilisation des Lasers Intenses, CNRS, École Polytechnique (France); O. Guilbaud, M. Pittman, S. Kazamias, K. Cassou, S. Daboussi, D. Ros, LASERIX-CLUPS, CNRS, Univ. Paris-Sud 11 (France); A. Klisnick, ISMO, CNRS, Univ. Paris-Sud 11 (France)

$81401 \mathrm{C}$ Spectral modeling of Fe XVII pumped by a free-electron x-ray laser [8140-48]

J. Clementson, Lawrence Livermore National Lab. (United States)

8140 1D Modeling of pressure induced phase matching in high harmonic generation [8140-49]

S. Kazamias, S. Daboussi, O. Guilbaud, K. Cassou, Lab. de Physique des Gaz et des Plasmas, CNRS, Univ. Paris-Sud 11 (France) and LASERIX-CLUPS, CNRS, Univ. Paris-Sud 11 (France); M. Pittman, LASERIX-CLUPS, CNRS, Univ. Paris-Sud 1 (France); D. Ros, Lab. de Physique des Gaz et des Plasmas, CNRS, Univ. Paris-Sud 11 (France) and LASERIX-CLUPS, CNRS, Univ. Paris-Sud 11 (France); B. Cros, G. Maynard, Lab. de Physique des Gaz et des Plasmas, CNRS, Univ. Paris-Sud 11 (France)

Author Index 


\title{
Conference Committee
}

\author{
Program Track Chair
}

Carolyn A. MacDonald, University at Albany (United States)

Conference Chairs

James Dunn, Lawrence Livermore National Laboratory (United States)

Annie Klisnick, ISMO, CNRS, University Paris-Sud 11 (France)

Program Committee

Hiroyuki Daido, Japan Atomic Energy Agency (Japan)

Sylvie Jacquemot, Ecole Polytechnique (France)

Do-Kyeong Ko, Gwangju Institute of Science and Technology

(Korea, Republic of)

Ciaran L. S. Lewis, Queen's University Belfast (United Kingdom)

Katsumi Midorikawa, RIKEN (Japan)

Stefan Moeller, SLAC National Accelerator Laboratory (United States)

Peter-Viktor Nickles, Gwangju Institute of Science and Technology

(Korea, Republic of)

Joseph Nilsen, Lawrence Livermore National Laboratory

(United States)

Geoffrey J. Pert, The University of York (United Kingdom)

Jorge J. Rocca, Colorado State University (United States)

Szymon Suckewer, Princeton University (United States)

Gregory J. Tallents, The University of York (United Kingdom)

Alexander Vladimirovich Vinogradov, P.N. Lebedev Physical Institute (Russian Federation)

\section{Session Chairs}

1 Free Electron Lasers

James Dunn, Lawrence Livermore National Laboratory (United States)

2 Seeding of X-ray Lasers

Jorge J. Rocca, Colorado State University (United States)

3 Harmonics and Short Wavelength Lasers

Sylvie Jacquemot, Ecole Polytechnique (France)

$4 \quad$ X-ray Laser Applications I

Annie Klisnick, ISMO, CNRS, University Paris-Sud 11 (France) 
$5 \quad$ Plasma-Based X-ray Laser Sources I

Gregory J. Tallents, The University of York (United Kingdom)

$6 \quad$ Free Electron Lasers: Experiments and Diagnostics

Katsumi Midorikawa, RIKEN (Japan)

$7 \quad$ X-ray Laser Applications II

Joseph Nilsen, Lawrence Livermore National Laboratory

(United States)

8 Plasma-Based X-ray Laser Sources II

Stefan Moeller, SLAC National Accelerator Laboratory (United States) 


\section{Introduction}

The X-ray Lasers and Coherent X-ray Sources: Development and Applications conference held in San Diego, California on 23-25 August, 2011, continues the series of meetings over the last two decades dedicated to new developments and applications of $x$-ray lasers and other coherent $x$-ray sources. The scope of this meeting was to present state-of-the-art results in the generation of intense $x$ rays in areas of plasma-based $x$-ray lasers, $4^{\text {th }}$ generation accelerator-based sources and higher order harmonic $(\mathrm{HOH})$ generation.

Although this has been the conference objective in recent meetings, this year the conference title was changed from the previous Soft $X$-ray Laser and Applications VIII meeting, held in 2009. The intent was to enhance the goal to bring different communities working in plasma-based $x$-ray lasers and sources, $\mathrm{HOH}$ and free electron laser (FEL) research together in areas of overlap and common interest: applications to ultrafast, high-intensity interaction with matter, innovative instrumentation for optics and detectors, or modeling and theory. This volume reviews the state of the field in 2011 .

There were new and exciting presentations in the eight oral and extended poster sessions addressing the main research themes of Free Electron Lasers, Seeding of $X$-ray Lasers, Harmonics and Short Wavelength Lasers, X-ray Laser Applications and Plasma-based X-ray Laser Sources. In the Free Electron Lasers sessions, the first demonstration of the inner shell photo-ionized x-ray laser scheme, first proposed in 1967, was shown for neon Ka. This is an extraordinary result for a scheme that has eluded researchers for many decades. This gives insight into the kinetics of this high-efficiency pumping scheme that will lead to future experiments scaled to higher $Z$ and 2-color irradiation. Many new Linac Coherent Light Source experiments were reported producing data from the recently commissioned end stations. These included new results showing lensless imaging of biological samples at hard x-ray energies.

The Seeding of X-ray Lasers topic, where a $\mathrm{HOH}$ seed is wavelength-matched and injected into a plasma amplifier, continues to be of strong interest. New modeling results with supporting experiments to better characterize and understand the scheme were reported by several groups. An advanced scheme of chirped pulse amplification of an x-ray laser was proposed to increase output to milli-joules in ultrafast $\sim 200$ fs duration. $\mathrm{HOH}$ source development was reported in Harmonics and Short Wavelength Lasers using relativistic laser intensities into a gas jet. Applications to attosecond physics as well as advances in lensless, nanoscale imaging were described. 
In the various $X$-ray Lasers Applications sessions, there were overlaps and links developing in the science communities where similar types of experiments were proposed for use on FELs, x-ray lasers and $\mathrm{HOH}$ sources. Lensless imaging has been mentioned for FELs and HOHs. Others included opacity measurements, warm dense matter and high energy density plasma creation experiments. Notable results were presented using novel soft $x$-ray laser-ablated nanoscale mass spectroscopy techniques demonstrated in two dimensions with high sensitivity. New results and refinements were presented in high-resolution microscopy, imaging, material properties as well as measuring time-resolved dynamic changes in matter.

Plasma-based X-ray Laser Sources continue to make progress to shorter wavelengths and higher repetition rates with substantially lower pump energies. Results for saturated x-ray lasers, operating at $8 \mathrm{~nm}$, were reported by several groups. Coherence and characterization experimental results were described that will enhance the continued development.

We gratefully acknowledge the continued support of SPIE for the field of x-ray lasers. We thank SPIE for the outstanding organization of the conference at all stages as well as the considerable efforts of the staff towards the publication of the proceedings volume. We would like to thank the Program Committee for their support and guidance and to the session chairs for their help in the running of the conference. We give our thanks to the many participants for their high quality scientific contributions to the 2011 meeting.

James Dunn Annie Klisnick 
Plenary Paper

\title{
BIOMEDICAL SPECTRAL X-RAY IMAGING; PROMISES AND CHALLENGES
}

\author{
Steven M. Jorgensen, Diane R. Eaker, Erik L. Ritman \\ Department of Physiology and Biomedical Engineering, Mayo Clinic College of Medicine, \\ Rochester MN 55905
}

\begin{abstract}
Imaging arrays with sub-millimeter detector pixels that count and allocate energy to each detected photon are now being introduced into biomedical computed tomography scanners. Consequently, bremsstrahlung x-ray can provide the advantages of simultaneous recording of multiple quasi-monochromatic x-ray images which can be used for identification of various materials within the image field. This capability increases the inherent contrast within biomedical CT images and also introduces the ability to use high atomic weight "foreign" elements (e.g., strontium) which are surrogates for "native" biological elements (e.g., calcium) to monitor tissue function (e.g., bone deposition). Challenges for this methodology include limited maximum fluence due to photon pile-up, charge-sharing between contiguous pixels and heterogeneous pixel characteristics due to manufacturing difficulties.
\end{abstract}

Keywords: Dual-Energy X-ray, Micro-CT, Clinical CT, X-ray Scatter, Photon Counting, Beam Hardening, Photon Pile-up, Charge sharing, Kedge, X-ray fluorescence

\section{INTRODUCTION}

Spectral x-ray imaging involves allocating the photon energy to each photon detected. Consequently, photon counting is an integral component of this approach. Spectral tomographic imaging has been used for decades in nuclear imaging in which different monochromatic gamma rays are distinguished so that Compton scatter (which has lower photon energy than the monochromatic gamma ray generated by the radionuclide) can be separated from the gamma ray of interest. ${ }^{1}$ It has also been used in dual energy x-ray CT imaging for enhancing the contrast of elements with a $\mathrm{K}$ absorption edge (Figure 1). ${ }^{2}$

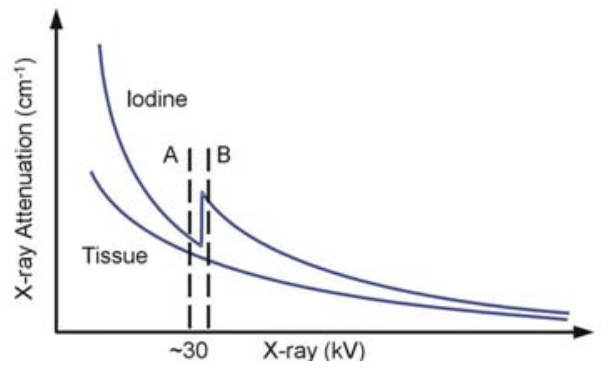

\begin{abstract}
Figure 1 - A schematic representation of the change in $x$-ray attenuation coefficient with change in $\mathrm{x}$-ray photon energy for iodine and for soft tissue. If $x$-ray images are generated from a narrow bandwidth x-ray spectrum, one just below and another just above the photon energy of iodine's K absorption edge, then their subtraction essentially removes the soft tissue but leaves a significant fraction of the iodine component of the image.
\end{abstract}

However, as illustrated in Figure 2, it's important to note that up to now the dual energy x-ray subtraction imaging involved broad spectrum x-ray and did not involve photon counting. The major x-ray CT companies are marketing clinical CT scanners which can utilize dual energy subtraction for separation of the iodine in intravascular contrast agent from calcium accumulations in diseased arterial vessel walls or discriminate different material contents of kidney stones and tissue deposits such as occur in gout. ${ }^{4,5}$ The Siemens scanner ${ }^{6}$ achieves this by use of two x-ray sources with one operating at up to $140 \mathrm{kVp}$ and a tin filter and the other tube operated at lower voltage, e.g., $80 \mathrm{kVp}$. The Philips scanner ${ }^{7}$ uses a single $\mathrm{x}$-ray source with a dual layer detector array in which the detector material in the 
superficial array is selected for capturing low energy photons and the deep array selected for capturing the high energy photons.
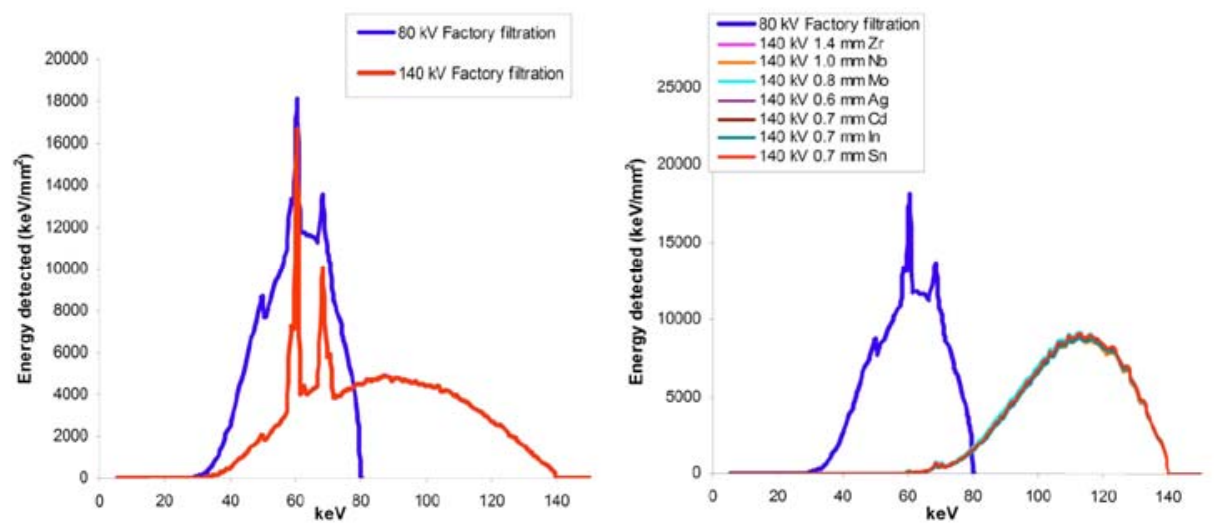

Figure 2 - Left panel shows a typical x-ray spectrum of a clinical CT scanner's x-ray source operated at 80 and $140 \mathrm{kVp}$. These sources were both filtered with a layer of aluminum. Note the considerable overlap of the two spectra. The right panel shows the two spectra with the $140 \mathrm{kVp}$ spectrum after filtration through various thin, fairly high atomic weight, metal foils. Reproduced with permission from Ref 3.

An improvement to this approach was implemented in x-ray imaging such as mammography and micro-CT which utilize lower photon energies. ${ }^{8}$ Figure 3 shows that the bandwidth of the bremsstrahlung can be greatly narrowed by use of the K $\alpha$ emission of a selected metal in the x-ray source's anode along with a metal foil filter with a Kedge just above the $\mathrm{K} \alpha$ of the anode.

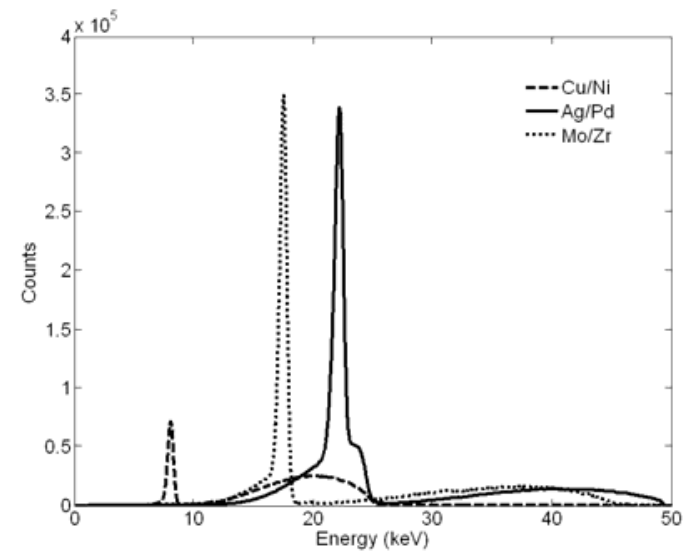

Figure 3 - Three $\mathrm{x}$-ray spectra generated with anodes made of copper, molybdenum and silver. These metals have $\mathrm{K} \alpha$ fluorescence peaks at $8.03 \& 8.05 \mathrm{keV}$ for copper, $17.4 \& 17.5 \mathrm{keV}$ for molybdenum and $22.16 \& 21.99 \mathrm{keV}$ for silver. When these spectra are filtered by a foil of nickel (Kedge $8.3 \mathrm{keV}$ ), zirconium (Kedge $18.0 \mathrm{keV}$ ) or palladium (Kedge $24.4 \mathrm{keV}$ ) respectively much of the spectrum above and below the $\mathrm{K} \alpha$ peak is preferentially suppressed leaving these quasi-monochromatic x-ray spectra. Reproduced with permission from Ref. 9.

The advantage of this approach is that there is greatly reduced beam hardening (i.e., the spectral content of penetrating $\mathrm{x}$-ray shifts to higher energies with increasing thickness of the transilluminated object. In CT beam hardening results in the "cupping" artifact ${ }^{10}$ in which the CT image grey scale varies with location within an object of uniform attenuation coefficient. These clinical and micro-CT approaches, however, do not fully exploit the power of spectral imaging because the bandwidth of the $\mathrm{x}$-ray spectra used are still quite broad. Importantly, synchrotron $\mathrm{x}$-ray imaging methods (which has sufficiently high flux to allow imaging at very narrow (e.g., $50 \mathrm{eV}$ ) bandwidth ${ }^{11}$ ) are limited by the fact that they typically do not count photons. Counting photons is important because it reduces the quantum noise to that of the detected photons and eliminates electronic noise of the imaging detector system. ${ }^{12}$ 
In recent years detector arrays have been developed that have x-ray photon counting and energy discriminating capabilities. ${ }^{13}$ This development now opens the door to fully exploiting spectral $\mathrm{x}$-ray imaging capabilities for high spatial resolution $\mathrm{x}$-ray imaging. The following description of one such imaging array illustrates the potential and technical challenges associated with this approach.

\section{SPECIFIC METHODOLOGY}

\subsection{Methodological difficulties}

Figure 4 is a schematic of the Medipix x-ray detection array developed at CERN. It shows a layer of material (silicon in this example) which captures x-ray photons and transports the resulting shower of electrons to the deeper surface by virtue of the potential gradient imposed across the material. The number of electrons in that shower being proportional to the $\mathrm{x}$-ray photon energy.
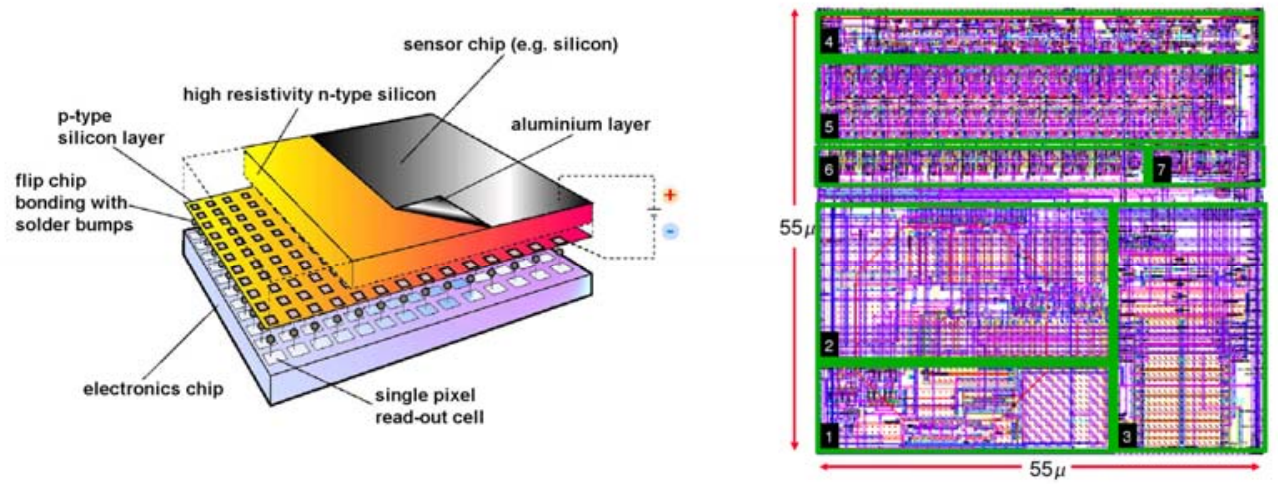

ARRAY

PIXEL

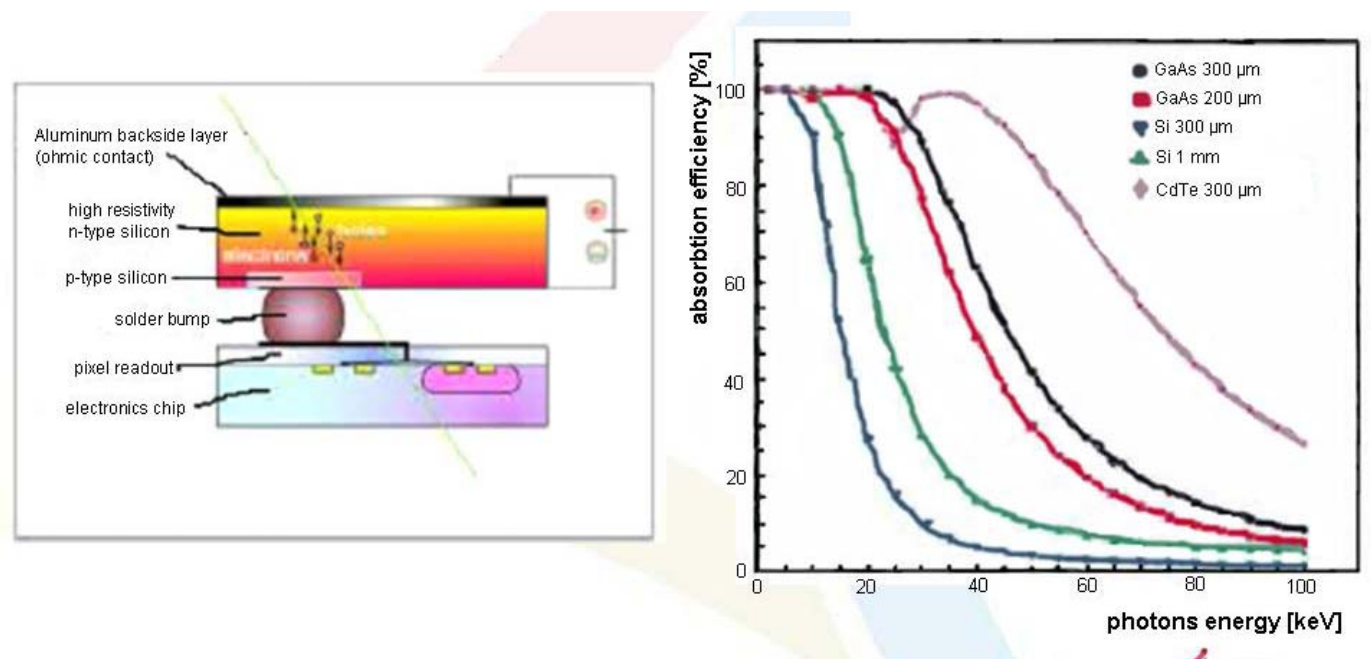

Figure 4-Left upper panel is a schematic representation of a Medipix chip and its components. See text for details. Right upper panel is a magnified view of one of the $55 \times 55 \mu \mathrm{m}^{2}$ CMOS circuits underlying each detector "pixel". The left lower panel is a schematic representation of the bump bond between the x-ray-toelectron converting material and the CMOS circuitry. The right lower panel shows the absorption efficiency of several candidate material for converting the x-ray to electrons. (Right upper panel reproduced with permission from Ref. 14. Lower panels, courtesy from Dr. A. P. Butler, Univ. Canterbury, Christchurch NZ). 


\subsubsection{Charge sharing}

As illustrated in Figure 5 the charge cloud generated by the $\mathrm{x}$-ray photon is sensed by one or several contiguous CMOS circuits in a 256x256 array beneath the layer. This circuit counts the number of clouds that fall above the program-selectable energy threshold and converts their charge to $\mathrm{cm}$ index of photon energy. These data are stored in a memory with a capacity for the information about 8000 photons.

The Medipix3 detector array's CMOS circuit also "look" at their contiguous neighbors to see if there is coincident detection of photons. This is important as the cloud of electrons may fall on adjacent pixels.

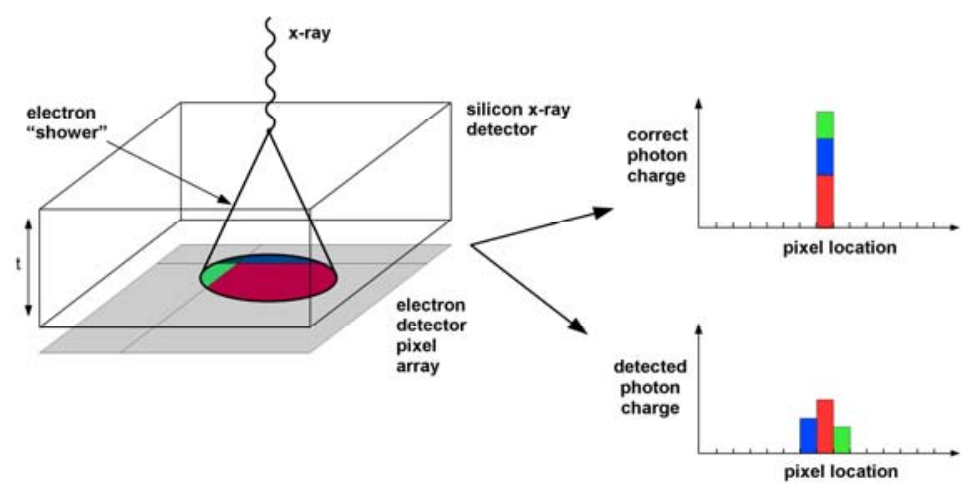

Figure 5 - Left panel is a schematic representation of the shower of electrons generated by the absorption of one x-ray photon. Note that this shower can affect the domain of several contiguous pixels. The right lower panel shows the charge recorded in each of those pixels. The right upper panel shows that one of the pixels is allocated one photon with an energy equal to the sum of the three, coincidentally recorded, signals.

If taken at face value this would result in several lower energy photons being detected. The CMOS circuit determines that they are from one photon, thus by adding the values and allocating the sum to the pixel with the highest number of electrons, deals with this charge sharing problem. Figure 6 illustrates the impact of this capability.
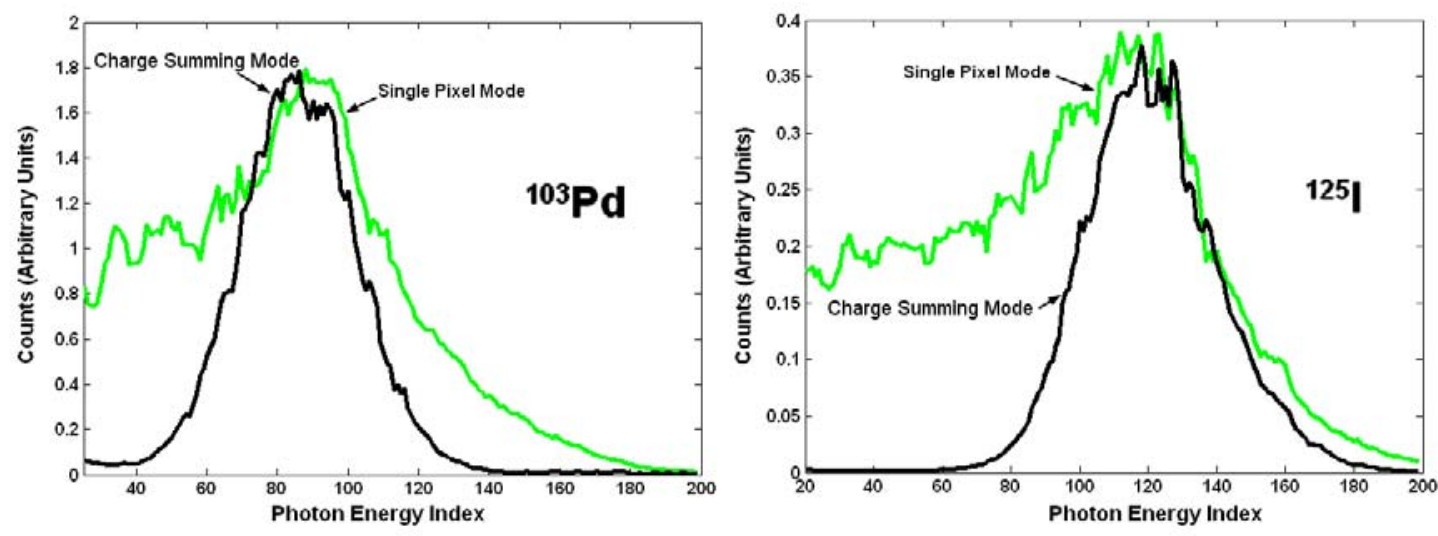

Figure 6 - Left panel shows the green plot spectrum recorded with the Medipix 3 chip of a palladium 103 source which generates predominantly $20 \mathrm{keV}$ gamma rays and the right panel shows the green plot spectrum of an iodine 125 source which predominantly generates $27 \mathrm{keV}$ gamma rays. Note, the "shoulder" of low energy photons which result from the charge-sharing artifact of the chip operated in the "single pixel mode". The black spectra are those generated when the chip is operated in the "charge summing mode". The abscissa's scale is in analog to digital units, which can be calibrated from these gamma ray emission responses. 


\subsubsection{Charge 'pile-up'}

Another issue is the problem of charge pile-up ${ }^{15,16}$ in which two photons strike a pixel simultaneously and thus are detected as a single photon with the energy equal to the sum of the two photons. Figure 7 illustrates the impact of the pile-up phenomenon. In addition to reporting fewer photons than actually arrive at the detector, there is a skewing from lower to higher photon energies in the reported spectrum. This can only be corrected at the CMOS level by making it faster or by reducing the size of the detector pixel. Consequently, we deal with this by reducing the rate of photon delivery to a level at which the pile up effect is negligible. Pile-up and charge sharing have opposite consequences. Pile-up is reduced with small detector pixels but charge sharing decreases with increased pixel size. Hence, pixel size must be matched to the imaging application.

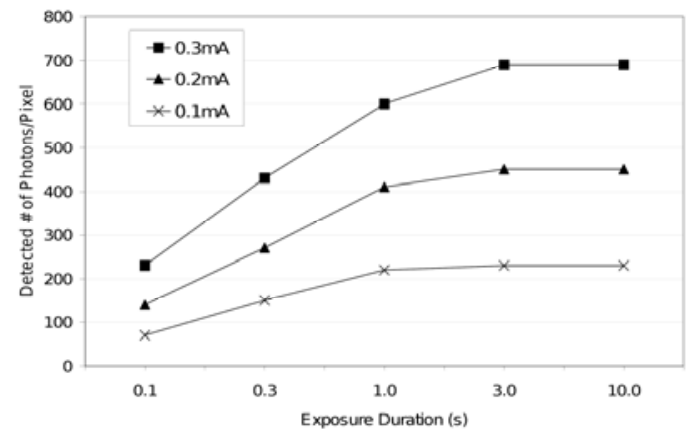

Figure 7 - Each of these curves was generated by exposing the chip to a constant number of photons, but at increasing rates of delivery by decreasing the distance of the x-ray source to the detector array and by proportionately reducing the time interval over which they were delivered. If there was no photon "pile-up" the number of photons detected should remain constant at all exposure rates, but as illustrated here the number detected decreased if those photons were delivered in less than 1 second under these exposure conditions. As the x-ray source current was increased we see a proportional increase in the number of photons detected and an appearance of the pile-up effort at lower exposure rates.

Figure 8 shows that increasing pile-up, resulting from increasing rate of delivery of photons caused by increased current in the x-ray source, results in skewing to the right of the $\mathrm{x}$-ray spectrum measured with the silicon-based MPX3 imaging array.

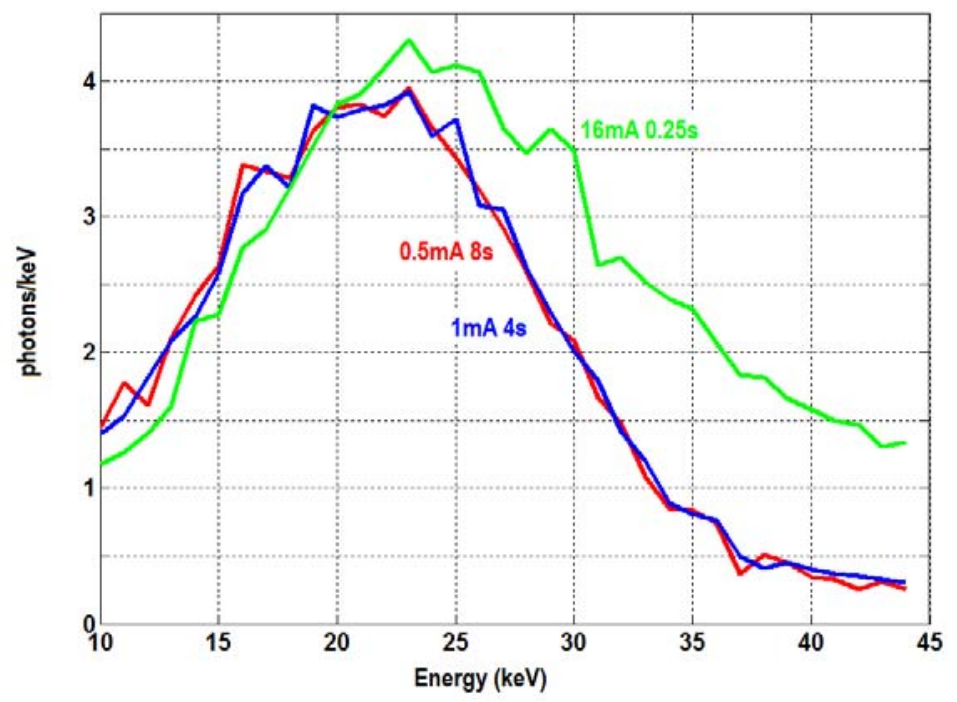

Figure 8 - The spectrum of the tungsten anode $\mathrm{X}$-ray source as conveyed with the Medipix3 imaging array when exposed to 4 $\mathrm{mAs}$ at $35 \mathrm{kVp}$, delivered at increasing $\mathrm{mA}$ settings for correspondingly shorter exposures so as to ensure equal total exposures. With increasing $\mathrm{mA}$ pile-up increases and results in the rightward skewing of the spectrum. The imaging array was operated in Charge Summing Mode.

\subsubsection{Non uniform pixel sensitivity}

Another technical issue is the heterogeneity of the individual pixel characteristic exposure to signal output curve. Ideally this input/output relationship is linear until it saturates beyond the capacity of the counter in the CMOS circuit. However due to manufacturing imperfections, the sensitivity of each pixel differs so that some saturate earlier than others when exposed to the same x-ray flux. Figure 9 shows that with increasing exposure the average signal from the array "plateaus" as more and more pixels reach their individual plateaus. However, if we expose the array in time slots that expose even the "weakest" pixels to just below the "knee" of their input/output curve, and repeat those exposures 
after down-loading after each exposure, we can get the linear relationship at increased exposure by summing those exposures.

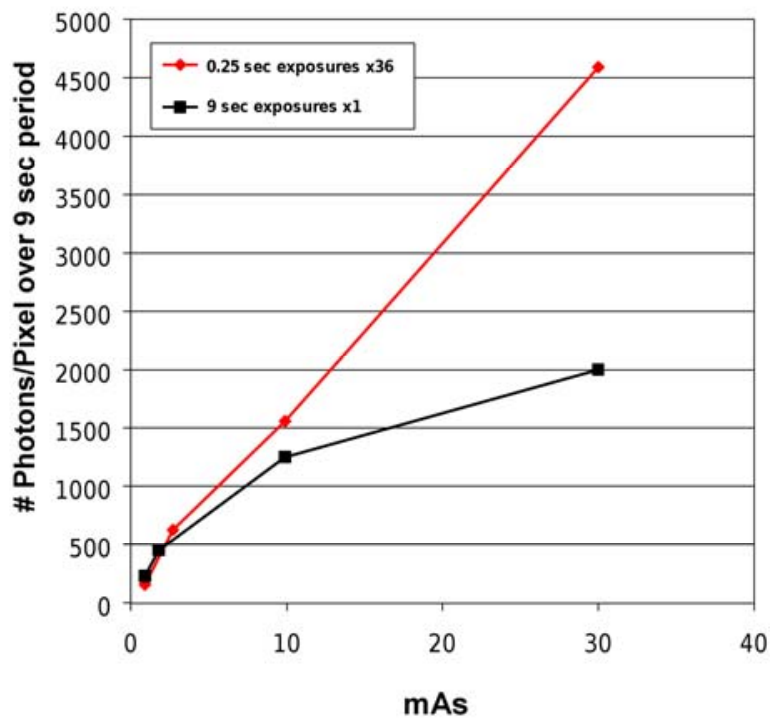

Figure 9 - The black curve indicates the impact of the heterogeneity of detector pixel saturation exposure as a function of total exposure. The red curve shows that if the same data are collected piecewise with a sequence of short-duration exposures, then the expected linear relationship results. See text for details.

\subsubsection{Detector fluorescence}

Finally, there is the problem of fluorescence and x-ray scatter with the detector material. ${ }^{16}$ Silicon, Galium and Arsenic have fluorescence energies below $10 \mathrm{keV}$ and hence are not of concern in micro-CT, mammography or clinical CT. However, Cadmium and Tellurium have fluorescence at about 23 and $27 \mathrm{keV}$, values which could significantly distort the photon energy information in micro-CT and mammography, but probably not significantly in clinical CT.

\subsection{Applications}

An immediate consequence of energy resolving x-ray imaging is the ability to eliminate the beam hardening artifact in CT. Figure 10 is a plot of CT image pixel grey-scale values along a diameter through a test phantom. If the full spectral width is used we get the "cupped" profile whereas if we used just a narrow bandwidth selected from that same exposure the "cupping " artifact is essentially eliminated. Note the increased noise in that profile - consistent with the fewer photons in the narrow bandwidth spectrum used in generating this tomogram. However, if we were to do a CT reconstruction for each of the multiple energy bins within that broad spectrum, and then added those images then the "cupping" artifact would still be eliminated and the noise would be essentially the same as the single broad spectrum data.

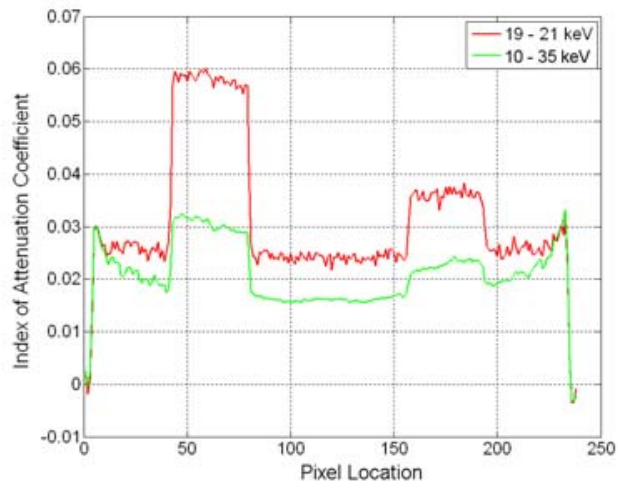

Figure 10 - The green profile is a CT value profile along a diameter of a plexiglas test phantom scanned with broad spectrum x-ray. It shows the cupping artifact due to beam hardening. The red profile is from the same diameter of the phantom, but from a $\mathrm{CT}$ image generated with the narrow bandwidth section selected from the broad spectrum scan data set. Note, the great reduction in beam hardening artifact and the increased noise (due to the fewer photons). 
Figure 11 illustrates the impact of multi-energy imaging on the ability to identify the signal due to an element with a $\mathrm{K}$-edge within the range of the spectrum. In this case rubidium, with a $\mathrm{K}$-edge at $15 \mathrm{keV}$, the characteristic increase in $\mathrm{CT}$ grey scale values as the photon energy increases through the K edge energy. In this case it identifies and discriminates the rubidium from potassium. A possible importance here is that rubidium is a biological surrogate for potassium and hence muscle cell activity could be monitored by quantitating the amount of rubidium incorporated into muscle, a mechanism used previously using NMR spectroscopy scans to measure the uptake or washout of $87 \mathrm{Rb} .{ }^{17}$
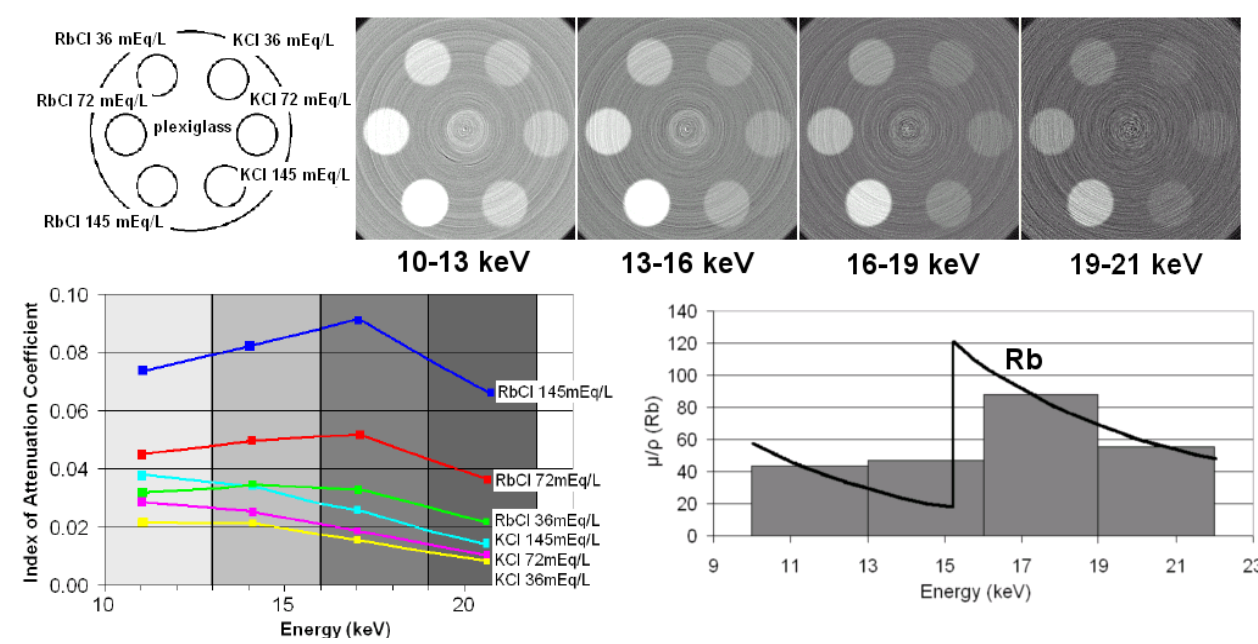

Figure 11 - Upper left panel is a schematic of the contents of a plexiglas test phantom containing samples of potassium and rubidium chloride solutions of different concentrations. 145 milli-equivalent is the intracellular concentration of potassium. The right upper panels show the quasi monochromatic CT images generated at increasing x-ray photon energy. The left lower panel shows the measured CT values and how these change with x-ray photon energy. The right lower panel uses the NIST ${ }^{18} \mathrm{~K}$-edge of rubidium and how this information is conveyed by the $3 \mathrm{keV}$-wide spectral "bins" used in this study. The loss of the clear Kedge results from the spectral width, but the attenuation decay as a function of increasing photon energy for rubidium clearly allows it to be distinguished from the potassium.

An exciting development is the use of gold-labeled nano-spheres, that are attached to antibodies targeted to specific cell types, which can be injected into the blood stream and then depositing preferentially in tissues such as cancer. ${ }^{19}$ The high attenuation coefficient of gold, combined with its $\mathrm{K}$ absorption edge of $80.7 \mathrm{keV}$, allows detection and discrimination from other sources of local increase in CT grey-scale value even at relatively low concentrations of the nano-spheres in the tissue. However, the concentration of the nano-spheres should exceed a certain minimum in order to prevent loss of specificity due to the partial volume effect resulting from CT image voxels being too large relative to the number of nano-spheres per voxel. Figure 12 illustrates this effect with a single gold-coated 15 micrometer diameter micro-sphere, in water, imaged at different voxel sizes.

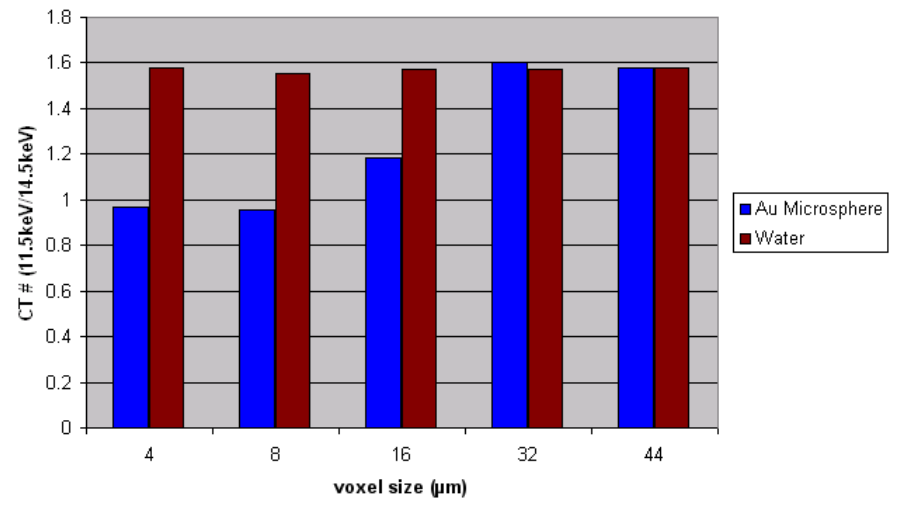

Figure 12 - a bar graph of the CT grey-scale values of a single voxel containing a 15 micrometer diameter, gold coated microsphere. If the micro-sphere were solid gold then detection of the microsphere in a larger voxel size would still be possible. 
Spectral imaging also has potential for greatly facilitating x-ray scatter imaging. Coherent x-ray scatter (as distinct from incoherent - i.e., Compton- scatter) can provide information about chemical bonds and of some repetitive submicron anatomical features. Figure 13 shows how this involves recording the $\mathrm{x}$-ray scatter at several angles of view away from the illuminating x-ray beam over a range of 0 to 20 degrees. Hence, a CT scan would involve rotation through 360 degrees using a single slice exposure. If bremsstrahlung is used the scatter recorded at each pixel will have multispectral information as well as being the integral of the scatter generated along a chord of the illuminated object cross section.

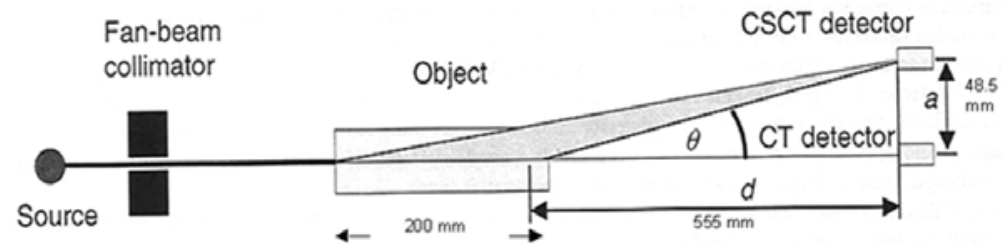

Figure 13 - A schematic of how a clinical multi-slice CT scanner can be converted to a single slice coherent x-ray scatter detection scanner. Reproduced with permission Ref. 20.

Figure 14 shows that if an energy discriminating detector is used, combined with a polycapillary x-ray optic collimator, ${ }^{21}$ then all necessary information can be recorded from one angle of view - the spectral information now providing the equivalent of the angle in the arrangement illustrated in Figure 13.

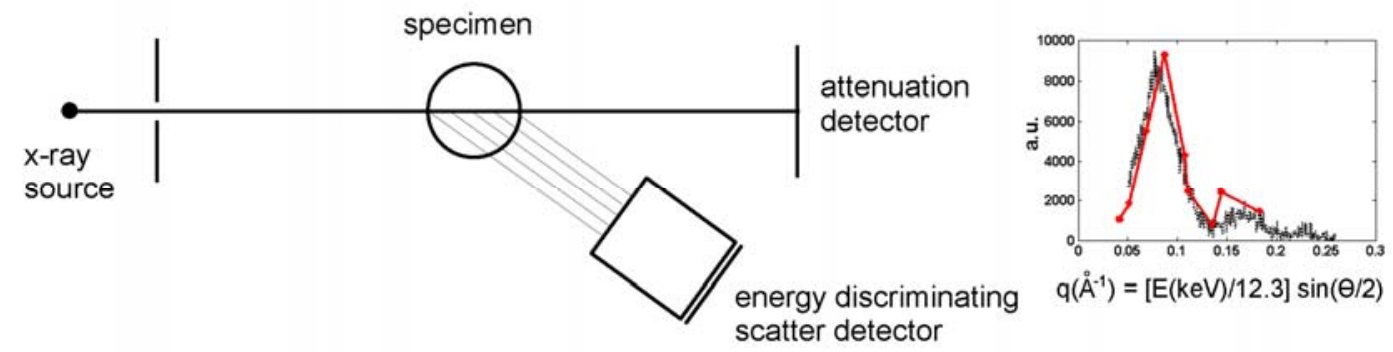

Figure 14 - A schematic of a planar x-ray exposure (seen edge on) and the scatter from that plane being observed via a collimator held at a fixed angle to the x-ray plane. The right panel shows how the spectral energy values can be used to generate the momentum transfer function for the material of lucite. The red profile was generated with the spectral imaging array at one angle and the black profile was generated with multi-angular data without energy discrimination. Modified and reproduced with permission from Ref. 22.

\section{DISCUSSION}

The overview of capabilities and technical challenges listed above suggests that the introduction of spectral x-ray imaging in clinical CT has potential for increasing the CT image contrast, signal to noise, accuracy of CT grey-scale values, and ability to identify and/or discriminate elements. This will expand the use of CT beyond the current anatomic information to increase the repertoire of functional information. Examples of the latter include quantitation of iron content in livers in hemachromatosis, discriminating iodine (in contrast agent) in arterial lumens from calcium in the arterial walls, and iron from calcium in arterial walls in atherosclerotic plaques. With this capability there will be stimulus for developing contrast agents based on lanthanide elements with $\mathrm{K}$ edges in the clinical $\mathrm{kV}$ ranges.

Consequently multiple contrast agents could be used simultaneously for use in dual indicator dilution techniques such as blood pool versus contrast excreted via the kidney or bile or diffusing into the extravascular space as an index of local endothelial permeability. The method can also be extended by labeling nano-particles (e.g., used to selectively 
attach to cancer cells) with a lanthanide element which can be readily detected and identified by its K-edge signature. Preliminary data and progress in manufacturing experience suggest that technical challenges can be overcome.

\section{ACKNOWLEDGEMENTS}

The research performed in Dr. Ritman's Laboratory was funded in part by NIH grants HL65342 and EB000305. We also acknowledge the contributions from coworkers Drs. C. H. McCollough, S. Leng, L. O. Lerman, B. Kantor and A. Lerman at Mayo Clinic College of Medicine and Drs. A. P. Butler and P. Butler from Christchurch University, New Zealand.

\section{REFERENCES}

[1] Berger, H. J., Gottschalk, A. and Zaret, B. L., "Dual radionuclide study of acute myocardial infarction: Comparison of thallium-201 and technetium-99m stannous pyrophosphate imaging in man," Ann. Intern. Med. 88, 145-154 (1978).

[2] Alvarez, R. E. and Macovski, A., "Energy selective reconstructions in x-ray computerized tomography," Phys. Med. Biol. 21, 733-744 (1976).

[3] Primak, A. N., Ramirez, Giraldo, J. C., Liu, X., Yu, L. and McCollough, C. H., "Improved dual-energy material discrimination for dual-source CT by means of additional spectral filtration," Med. Phys. 36(4), 1359-1369 (2009).

[4] Takahashi, N., Vrtiska, T. J., Kawashima, A., Hartman, R. P., Primak, A. N., Fletcher, J. G. and McCollough, C. H. " Detectability of urinary stones on virtual nonenhanced images generated at pyelographic-phase dual-energy CT," Radiology 256(1), 184-190 (2010).

[5] Bacani, A. K., McCollough, C. H., Glazebrook, K. N., Bond, J. R., Michet, C. J., Milks, J. and Manek, N. J., "Dual energy computed tomography for quantification of tissue urate deposits in tophaceous gout: help from modern physics in the management of an ancient disease," Rheumatol. Int. (2011), In Press.

[6] Flohr, T. G., Bruder, H., Streistorfer, K., Petersilka, M., Schmidt, B. and McCollough, C. M., "Image reconstruction and image quality evaluation for a dual source CT scanner," Med. Phys. 35(12), 5882-5897 (2008).

[7] Hidas, G., Eliakou, R., Dradoani, M., Coulon, P., Lemaiti, L., Gofrit, O. N., Poole, D. and Sosua, J., "Deterimations of renal stone composition with dual energy CT: In vivo analysis and comparison with $\mathrm{x}$-ray diffraction," Radiology 257, 394-401 (2010).

[8] Fewell, T. R. and Shesping, R. E., "A comparison of mammographic x-ray spectra," Radiology 128(1), 211-216 (1978).

[9] Cui, C-W., Jorgensen, S. M., Eaker, D. R. and Ritman, E. L., "Direct three-dimensional coherently scattered x-ray micro-tomography," Med. Physics 37(12), 6317-6322 (2010).

[10] Barrett, J. F. and Keat, N., "Artifacts in CT: recognition and avoidance," Radiographics 211, 1679-1691 (2004).

[11] Magaritondo, G., [Introduction to synchrotron radiation], Oxford University Press, New York, pp 280 (1988).

[12] Shikhaliev, P. M., Xu, T. and Molloi, S., "Photon counting computed tomography: concept and initial results," Med. Phys. 32(2), 427-436 (2005).

[13] Campbell, M., Heijne, E. H.M., Meddeler, G., Pernigotti, E. and Snoeys, W., "A readout chip for a 64 x 64 pixel matrix with 15-bit single Photon Counting,” IEEE Trans. Nucl. Sc. 45(3), 751-753 (1998).

[14] Ballabriga, R., Campbell, M., Heijne E. H. M., Llopart X. and Tlustos, L., "The Medipix3 prototype, a pixel readout chip working in single photon counting mode with improved spectrometric performance," IEEE Trans. Nucl. Sci. 54(5), 1824-1829 (2007).

[15] Taguchi, K., Frye, E. C., Wang, X., Iwanczyk, J. S. and Barber, W. C., "An analytic model of the effects of pulse pileup on the energy spectrum recorded by energy resolved photon counting x-ray detectors," Med. Phys. 37, $3957-$ 396 (2010).

[16] Greiffenberg, D., Cecilia, A., Zwerger, A., Fauler, A., dos Santos Rolo, T., Pelliccia, D., Vagovic, P., Simon, R., Baumbach, T. and Fiederle, M., "Characterization of Medipix2 assemblies with CdTe sensor using synchrotron radiation,” IEEE Nucl. Sc. Symp. Conf. Record: 2008, R12-49 (2008).

[17] Kupriyanov, V. V. and Gruwel, M. L. H., "Rubidium-87 magnetic resonance spectroscopy and imaging for analysis of Mamalian $\mathrm{K}^{+}$transport.” NMR Biomed. 18, 111-124 (2005).

[18] http://www.nist.gov/physlab/data/xraycoeff/index.cfm 
[19] Hainfeld, J. F., Slatkin, D. N., Focella, T. M. and Smilowitz, H. M. "Gold nanoparticles: a new X-ray contrast agent," Br. J. Radiol. 79, 248-253 (2006).

[20] Schlomka, J-P, Delfs, J., Barschdorf, H., Thran, A. and Stevendaal, U., "Experimental feasibility study of energyresolved fan-beam coherent scatter computed tomography," Proc. SPIE 5535, 410-423 (2004).

[21] Jorgensen, S. M., D. A. Reyes, D. A., C. A. MacDonald, C. A. and Ritman, E. L., "Micro-CT scanner with a focusing polycapillary x-ray optic," Proc. SPIE - Developments in X-Ray Tomogr. II 3772, 158-166 (1999).

[22] Eaker, D. R., Jorgensen, S. M., Butler, A. P. H. and Ritman, E. L., "Tomographic imaging of coherent x-ray scatter momentum transfer distribution using spectral x-ray detection and polycapillary optic," Proc. SPIE,

Developments in X-ray Tomogr. VII 7804, 78041O-1-78041O-7 (2010). 